\title{
Operating flow of live operation of transmission line with series of special tools
}

\author{
Ma Jun ${ }^{1}$, Shi Yonggang ${ }^{1}$, Yu Liang ${ }^{1}$, Dong Gang ${ }^{1}$, Gong Fuxing ${ }^{1}$, Wei Kegang ${ }^{1}$, Su Xin ${ }^{1}$, An Shoutong ${ }^{1}$ \\ ${ }^{1}$ State Grid Tonghua Power Supply Compan, Tonghua, Jilin, 134000, China \\ ${ }^{2}$ University of Edinburgh, Architecture, Minto House, 20 Chambers Street, Edinburgh
}

\begin{abstract}
In view of the current characteristics of live operation of transmission lines and the problems of the use of series of special appliances without stipulations, etc. In this paper, the operation flow of live operation of transmission line using a series of special tools is presented.This article elaborates the operation process from seven aspects: scope of application, operation method, labor combination, operation process, safety measures, dangerous points, control measures and necessary tools.It solves a series of problems in carrying out live operation of transmission lines with a series of special tools.
\end{abstract}

\section{Introduction}

It has become a necessary trend to carry out live operation of transmission lines by using series of special tools. This mode of operation can ensure reliable and continuous power supply to users of transmission lines and reduce the economic losses caused by power outage maintenance. This method can also eliminate the shortcomings of transmission lines in time, improve the safety of transmission line operation, and improve the reliability of overhead transmission lines. The implementation of live operation has high flexibility, and personnel and machinery can better balance the work tasks according to the plan[1-9].

However, when using a series of special tools to carry out live operation of transmission lines, there is no designated operation process, the implementation of the work is not standardized, and there are potential safety hazards in the work. Therefore, according to the working characteristics of the series of special tools used in live operation of transmission lines, this paper formulates the operating process of live operation of transmission lines using series of special tools[10-13].

\section{Operating Regulations for Live Operation of Transmission Lines Using Series of Special Tools}

\subsection{Field Operation Regulations for Live Replacement of Whole Strings of Tensile Insulators for $66 \mathrm{KV}$ Lines}

The scope of application of this regulation is to replace tension insulators for $66 \mathrm{KV}$ transmission lines. The operation method of this work is a ground potential operation method. A total of six staff are required. One person is in charge of the work, two electricians are on the tower. They are numbered 1 and 2 respectively, and three electricians are on the ground.

Read out the work ticket, explain the operation method, safety precautions and hazard control measures[14-16]. No. 1 electrician belt transmission rope is mounted on the tower, and the transmission rope is hung in an appropriate position.No. 2 electrician goes to the tower. The ground electrician passes the tools up to the tower. After 1 and 2 electricians cooperate with installing fixtures and checking correctly, 2 electricians use operating rods to remove the spring pins on the wire side. No. 1 electrician removes the spring pin on the side of the crossbar. No. 1 electrician tightens clamp to disconnect insulator from conductor. After the insulator strings are updated on the ground, they are sent to the towing bottle rack to be put in place with the cooperation of the electrician on the pole and tower and the electrician on the ground. No. 2 electrician operates pole to connect insulator string with bowl head. No. 1 electrician relaxes clamp to force insulator. No. 2 electrician operates pole to install wire side spring pin, and No. 1 electrician installs cross-arm side spring pin. After checking the connection of each part, remove the tool and transmit it to the underground. No. 1 and No. 2 electricians come down to the tower and the work is over.

The person in charge of the work shall contact the dispatcher, and the operation shall be allowed only after permission. Insulation tools should be qualified in all tests. Detailed appearance inspection should be carried out before field operation. Dry towels should be wiped clean. The insulation resistance should not be less than 700 megaohms measured by 2500 volt shaking meter. Operators on the tower should wear a full set of qualified uniforms, and the connections between the parts should be reliable. The person in charge of the work (guardian) shall strictly guard the staff. Staff members should 
concentrate on obeying command. The safe distance between human body and electrified body must be more than 0.7 meters. After the effective length of the insulated operating rod is quite high and the clamping force of the 1 meters is loaded, the stress of each part should be inspected in detail. Field staff should wear safety helmet.

Table 1. Required tools.

\begin{tabular}{cccccc}
\hline Serial number & Tool name & Specification type & Unit & Quantity & Remarks column \\
\hline $\mathbf{1}$ & Airfoil fixture & HDL-60 & Set & 1 & \\
$\mathbf{2}$ & Transfer rope & $\phi 14$ & Set & 1 & \\
$\mathbf{3}$ & Operating lever & & Pair & 1 & \\
$\mathbf{4}$ & Picking pin & & Handful & 1 &
\end{tabular}

Dangerous points of work and control measures. Prevent falling from high altitude. Operators on poles and towers must fasten their seat belts to prevent them from pulling out or being cut. When climbing the tower pole, check whether the foot nails are firm or not. Prevent slippage when using foot buckle to climb cement pole. Personal telegram. Regular withstand voltage test of insulating tools is qualified, and there is no problem in appearance inspection and test before use. Minimum safe distance for operator to live body: $66 \mathrm{kV}, 0.7 \mathrm{~m}$. Insulation tool keeps minimum effective insulation length, operating rod: $66 \mathrm{kV}, 1.0 \mathrm{~m}$. Insulation loadbearing tool insulation rope: $66 \mathrm{kV}, 0.7 \mathrm{~m}$. Special guardianship shall be set up, and special guardians shall be added to the poles and towers when ground command is difficult. Work in good weather. The wire fell off. The tightening wire tool must be qualified in mechanical strength and reliable in both ends. After replacing the insulator, carefully check that the front end ball head, pin, spring pin and pin pin are properly installed. Losing tools and materials hurts people. The ropes and pulleys for transmission should be placed reliably. Tools, materials, insulators and so on must be firmly tied to prevent falling off. Operators should wear safety hats. No one is allowed to stay below. Transfer tools and materials should be carried out outside the conductor. The required tools are shown in Table 1.

\subsection{Field Operation Regulations for Live Replacement of Tensile Insulators for $\mathbf{2 2 0}$ KV Lines}

The scope of application of this regulation is $220 \mathrm{KV}$ transmission line to replace tension insulators. The working method of this work is equipotential working method. A total of seven staff are required. One person is in charge of the work, two electricians are on the tower.
They are numbered 1 and 2, one electrician with equal potential is numbered 3 , and three electricians are on the ground.

Ground electricians transfer tools to the tower, and 1, 2 and 3 electricians cooperate to install insulating poles and insulating ladders. No. 3 electrician enters the electric field along the insulating hard ladder. No. 1 and No. 3 electricians cooperate to install big knife clamps and hang bottle hooks. Tighten the lead screw. Electricians No. 1 and No. 3 pull out the spring pins at both ends of the insulator string to separate the insulator string from the connecting plates on both sides. The No. 2 electrician cooperates with the ground electrician. The ground electrician uses manual grinding, tightens the sliding rope of the holding pole, and replaces the old and new insulator strings. Insulator string is in place. Electricians No. 1 and No. 3 install spring pins on both sides to relax the lead screw.

Before work, the person in charge of the work should contact the dispatcher and request the shutdown of reclosure. Only after permission can the work be done. Operators on the tower should wear qualified uniforms and ensure that all parts are firmly and reliably connected. The safe distance between the human body and the electrified body, as well as between the equipped personnel and the grounding body must be more than 1.8 meters. Equivalents maintain a safe distance of more than 2.5 meters to their neighbors, and the minimum distance of the combined clearance is 2.1 meters. After the tool and the holding rod are stressed, the force of each part should be checked in detail, and the work can be done without abnormality.

The danger points and control measures of this work are the same as that of live replacement of a whole series of tension insulators for $66 \mathrm{KV}$ transmission lines. The required tools are shown in Table 2.

Table 2. Required tools.

\begin{tabular}{cccccc}
\hline Serial number & Tool name & Specification type & Unit & Quantity & Remarks column \\
\hline $\mathbf{1}$ & Broadsword fixture & $220 \mathrm{kV}$ & Set & 1 & Tie rod \\
$\mathbf{2}$ & Insulating pole & $220 \mathrm{kV}$ & Set & 1 & \\
$\mathbf{3}$ & Transfer rope & $\phi 14$ & Set & 1 & \\
$\mathbf{4}$ & Transfer rope & $\phi 16$ & Set & 1 & Including bottle hooks \\
$\mathbf{5}$ & Horizontal Insulated Hard Ladder & $4.5 \mathrm{~m}$ & Pair & 1 & \\
$\mathbf{6}$ & Manual milling & $0.5 \mathrm{t}$ & Set & 1 & \\
$\mathbf{7}$ & Shielding clothing & & Set & 3 &
\end{tabular}




\section{Conclusion}

Operating rules are strict procedures for any operation. Anyone who performs this task strictly follows this procedure. Any tools used during the period and when to use such tools are specified in detail[17-20]. Strict operation is actually a detailed description of the operation process, supplemented by various illustrations, different people in the same work, whether the whole process or the final processing results should be the same. This is also the goal expected to be achieved in the formulation of operational procedures. This paper puts forward a series of special tools for live operation of transmission lines. Through this regulation, live operation of transmission lines can be carried out safely and efficiently. Effective completion of live work objectives.

\section{References}

1. Kan $\mathrm{H}$, Miyamoto $\mathrm{T}$. Proposals for an improvement in transformer diagnosis using dissolved gas analysis (DGA)[J]. IEEE Electrical Insulation Magazine, 1995, 11(6): 15 21.

2. Ward S A. Evaluating transformer condition using DGA oil analysis[C]// Electrical Insulation and Dielectric Phenomena, 2003 Report. Conference on. IEEE Xplore, 2003: 463 468.

3. Nemeth B, Laboncz S, Kiss I . Condition monitoring of power transformers using DGA and Fuzzy logic[C]// Electrical Insulation Conference, 2009. Eic. IEEE, 2009: 373 376.

4. Cousens R D, Moerkerk M. Sampling Strategy Is Important for Producing Weed Maps : A Case Study Using Kriging[J]. Weed Science, 2016, 50(4): 542 546.

5. Jeong S, Murayama M, Yamamoto K. Efficient Optimization Design Method Using Kriging Model[J] . Journal of Aircraft, 2005, 42(2) : 413 420.

6. Hinton G, Vinyals O, Dean J. Distilling the Knowledge in a Neural Network[J] . Computer Science, 2015, 14(7): 38 39.

7. Fanning K, Cogge K O, Srivastava R. Detection of Management Fraud : A Neural Network Approach $[\mathrm{J}]$. Intelligent Systems in Accounting Finance \& Management, 2015, 4(2): 113 126.

8. Demuth H B, Beale M H, De Jess O, et al. Neural Network Design[J]. 2014(4): 357.

9. $\mathrm{Hu} \mathrm{W}$ P, Yin $\mathrm{X} \mathrm{G}$, Zhang $\mathrm{Z}$, et al. Fault diagnosis of transformer insulation based on compensated fuzzy neural network[C]// Electrical Insulation and Dielectric Phenomena , 2003 Report. Conference on. IEEE Xplore, 2012 : 273 276.
10. Zheng $\mathrm{R}$, Zhao J, Zhao $\mathrm{T}$, et al . Power transformer fault diagnosis based on genetic support vector machine and gray artificial immune algorithm $[\mathrm{J}]$. Proceedings of the Csee, 2011, 31(7): 56 63.

11. Sun $\mathrm{Y} J$, Zhang $\mathrm{S}$, Miao C $\mathrm{X}$, et al . Improved BP Neural Network for Transformer Fault Diagnosis[J] . Journal of China University of Mining \& Technology, 2007, 17(01): 138 142.

12. Sherif Ghoneim . A New Approach of DGA Interpretation Technique for Transformer Fault Diagnosis[J] . International Journal of Electrical Power \& Energy Systems, 2016, 81(1): 265 274.

13. Kelly J J . Transformer Fault Diagnosis by Dissolved-Gas Analysis[J]. IEEE Transactions on Industry Applications, 1980, 6(6): 777 782.

14. Lin $\mathrm{C} \mathrm{E}$, Ling $\mathrm{J} \mathrm{M}$, Huang $\mathrm{C} \mathrm{L}$. An expert system for transformer fault diagnosis using dissolved gas analysis[J]. IEEE Transactions on Power Delivery (Institute of Electrical and Electronics Engineers); (United States), 1993, 8: 1(1): 231 238.

15. Duval M. Dissolved gas analysis: It can save your transformer[J] . IEEE Electrical Insulation Magazine, 1989, 5(6): 22 27.

16. Singh S, Bandyopadhyay M N. Dissolved gas analysis technique for incipient fault diagnosis in power transformers : A bibliographic survey[J]. IEEE Electrical Insulation Magazine, 2010, 26(6): 41 46.

17. Bhalla D, Bansal R K, Gupta H O. Function analysis based rule extraction from artificial neural networks for transformer incipient fault diagnosis $[\mathrm{J}]$. International Journal of Electrical Power \& Energy Systems , 2012, 43(1) : 1196 1203.

18. Seifeddine S, Khmais B, Abdelkader C. Power transformer fault diagnosis based on dissolved gas analysis by artificial neural network $[\mathrm{C}] / /$ First International Conference on Renewable Energies and Vehicular Technology . IEEE, 2012 : 230 236.

19. Hu W P, Yin X G, Zhang Z, et al. Fault diagnosis of transformer insulation based on compensated fuzzy neural network[C]// Electrical Insulation and Dielectric Phenomena , 2003 Report. Conference on. IEEE Xplore, 2012 : 273 276.

20. Zheng R, Zhao J, Zhao $\mathrm{T}$, et al . Power transformer fault diagnosis based on genetic support vector machine and gray artificial immune algorithm $[\mathrm{J}]$. Proceedings of the Csee, 2011 , 31(7): 56 63. 